\title{
Coarse Granular Cast Measurement
}

National Cancer Institute

\section{Source}

National Cancer Institute. Coarse Granular Cast Measurement. NCI Thesaurus. Code C74765.

The determination of the amount of coarse granular casts present in a urine sample. 